\title{
CONCEPTUALITY AND GENERALITY: A CRITICISM OF AN ARGUMENT FOR CONTENT DUALISM
}

\author{
LAURA DUHAU \\ Instituto de Investigaciones Filosóficas \\ Universidad Nacional Autónoma de México \\ duhau@filosoficas.unam.mx
}

SUMMARY: In this paper I discuss Heck's (2007) new argument for content dualism. This argument is based on the claim that conceptual states, but not perceptual states, meet Evans's Generality Constraint. Heck argues that this claim, together with the idea that the kind of content we should attribute to a mental state depends on which generalizations the state satisfies, implies that conceptual states and perceptual states have different kinds of contents. I argue, however, that it is unlikely that there is a plausible reading of the Generality Constraint under which it is non-trivially true both that conceptual states meet it and that perceptual states do not. Therefore, the soundness of Heck's argument is dubious.

KEY WORDS: Generality Constraint, conceptual states, perceptual states, conceptual content, nonconceptual content

RESUMEN: En este artículo discuto el nuevo argumento de Heck (2007) en favor del dualismo de contenido. Este argumento se basa en la afirmación de que los estados conceptuales, pero no los perceptuales, cumplen con el Requisito de Generalidad de Evans. Heck argumenta que esta afirmación, junto con la idea de que el tipo de contenido que debemos atribuir a un estado mental depende de las generalizaciones que el estado satisface, implica que los estados conceptuales tienen un tipo de contenido diferente del de los estados perceptuales. Yo argumento, sin embargo, que es poco probable que haya una interpretación convincente del Requisito de Generalidad según la cual sea verdadero pero no trivial tanto que los estados conceptuales lo satisfacen como que los perceptuales no. Por lo tanto, la solidez del argumento de Heck es dudosa.

PALABRAS CLAVE: Requisito de Generalidad, estados conceptuales, estados perceptuales, contenido conceptual, contenido no conceptual

In debates on philosophy of mind it is often claimed that although perceptual states and conceptual states are both representational states, there are differences between them that make them representational states of different kinds. Many share the intuition that perceptual states are richer and/or finer-grained than conceptual states. Moreover, perceptual states are usually claimed to be stimulusdependent and modality specific, ${ }^{1}$ while conceptual states are claimed

${ }^{1}$ Although not everyone agrees that all perceptual states are stimulus-dependent and modality specific. For concept empiricists such as Jesse Prinz, who use the term "perception" broadly to include not only externally and internally directed sensory representations, but also emotions and motor abilities, some perceptual states are not 
to be stimulus-independent and amodal. Perceptual processes are also claimed to be "cognitively impenetrable", i.e. what we perceive is not affected by beliefs or other conceptual states, as in the Muller-Lyer illusion, in which we perceive two lines as being of different lengths even when we come to believe that they are the same length.

Many philosophers (see for example Evans 1982, Martin 1993, Heck 2000, Kelly 2001, Tye 2005) argue from one or more of these assumed differences between perceptual states ${ }^{2}$ and conceptual states to the conclusion that these states have different kinds of content. These philosophers argue that conceptual states have only "conceptual content" and perceptual states have (at least some) "nonconceptual content", where the distinction between "conceptual content" and "nonconceptual content" is supposed to be substantial, i.e. not just the trivial difference that is captured by saying that conceptual states have conceptual state content and perceptual states have perceptual state content, which is merely a nominal difference. For example, Heck (2000) argues that the richness of perceptual states implies that at least some of their content is "nonconceptual" in the substantial sense. A similar line of argumentation has been used to claim that the fine-grainedness of perceptual states implies that the content of perception is "fully nonconceptual" (Evans 1982) or "partly nonconceptual" (Kelly 2001, Tye 2005). There are also arguments that take the cognitive impenetrability of perception to imply that perceptual states and beliefs are different, and then, with some further assumptions, argue from this idea to the idea that the difference between perceptual states and beliefs is that the content of the former is "nonconceptual" while the content of the latter is "fully conceptual" (Crane 1992).

I call the position that posits two substantially distinct kinds of content, conceptual content on the one hand and nonconceptual content on the other, "content dualism", and my general objective (that goes beyond the scope of this paper, as I will soon explain)

modality specific. Emotions, for example, which according to Prinz are perceptions of bodily states, can involve representations from different sense modalities (see his 2002 , pp. 120-122). In the same vein, if "perception" is used broadly to include mental images, it is not always stimulus-dependent. I thank an anonymous referee for bringing this to my attention.

${ }^{2}$ Most of these philosophers make the contrast between "perceptual experiences", rather than perceptual states, and conceptual states. Talking about experiences is purported to capture the idea that they are concerned with conscious perceptual states, or states at the personal level, rather than with perceptual representations at the subpersonal level, such as the images of the retina. In this paper, what I call perceptual states are perceptual experiences in this sense. 
is to argue against it. ${ }^{3}$ On my view, although perceptual states and conceptual states are different kinds of states, this is not due to differences in the content of those states. On my view, there is only one kind of content, one which need not be referred to as either conceptual or nonconceptual. ${ }^{4,5}$

A first step toward my general goal of showing that content dualism is wrong is to discard all the arguments that infer that perceptual states and conceptual states have different kinds of content from alleged differences between these kinds of states. I side with those that claim that most of these arguments are unsound, because they make an invalid inference from characteristics of states to characteristics of content. ${ }^{6}$

${ }^{3}$ The main reason to resist content dualism has to do with the justificatory relation between perceptual states and conceptual states. If perceptual states and conceptual states have different kinds of content, it is unclear how perceptual states can justify conceptual states, since it is difficult to conceive how different kinds of content could be inferentially related. Another reason for resisting content dualism has to do with parsimony. If positing different kinds of content is not explanatorily necessary (and I believe there is no good argument that it is), then we should resist doing it (see Robbins 2002 for an argument along these lines, regarding the explanatory superfluity of nonconceptual first-person content).

${ }^{4}$ Here the relevant difference between the view I would like to defend and content dualism is the one that Heck (2007) himself points out between the "content view" and the "state view". The idea is that content dualism (what Heck calls the "content view") claims that perceptual states and conceptual states have different kinds of content, while the "state view" (the view I favor) claims that the content of a subject's perceptual experience is not limited by the concepts she possesses. The state view is neutral on the question of what the contents of perceptual states should be taken to be (see p. 119).

${ }^{5}$ The case against content dualism is not new, although those that have argued against content dualism have not always been neutral on the question of the kind of content that they claim both conceptual states and perceptual states have. McDowell (1994) and Brewer (2005) have argued that both the content of conceptual states and the content of perceptual states are conceptual, while Stalnaker (1998) has defended the claim that both the content of conceptual states and the content of perceptual states are nonconceptual.

${ }^{6}$ See Byrne 2005 and Speaks 2005 for a thorough explanation of why the inference is invalid. The main reason is that even if it turns out to be the case that in order for a subject to have a belief with the content $p$ the subject needs to possess the concepts that canonically specify $p$, and in order for a subject to have a perceptual experience with content $p$ the subject does not need to possess the concepts that canonically specify $p$, this in itself does not entail anything about the kinds of contents that beliefs and perceptual experiences have, which can be of the same kind (see Speaks 2005, p. 361). In this spirit, and against what Heck 2000 argues, Heck 2007 acknowledges that we cannot directly conclude anything about the kind of content that perceptual states have from their alleged richness (see pp. 120 and 128). 
In this paper I want to discuss an argument proposed by Heck (2007) that tries to establish content dualism on the basis of an alleged difference between perceptual states and conceptual states that does not make such an invalid inference. I shall show that Heck's argument, though it does not commit the invalid inference mentioned above, fails on different grounds. Heck's argument is based on two main premises, one is a general assumption about what conditions would cause different kinds of mental states to have different kinds of content, and the other one claims that such conditions are in fact satisfied by conceptual states and perceptual states. More specifically, Heck's first premise states that conceptual states ${ }^{7}$ meet the Generality Constraint and perceptual states do not, and the second claims that this difference is sufficient for their having different kinds of content. I will raise a problem for Heck's argument that arises because it is not clear what the Generality Constraint is, and there is no acceptable construal of the Generality Constraint that makes non-trivially true both that conceptual states meet it and that perceptual states do not.

\section{Heck's New Argument for Content Dualism}

Heck (2007) argues that there is a difference between perceptual states and conceptual states (or cognitive states, as he calls them) that, together with his view of what would suffice for states to have contents of different kinds, implies that conceptual states and perceptual states have different kinds of content.

The basic structure of Heck's argument is thus as follows:

1. Conceptual states satisfy the Generality Constraint, and perceptual states do not.

2. If conceptual states satisfy the Generality Constraint and perceptual states do not, then conceptual states and perceptual states have different kinds of content.

Therefore,

3. Conceptual states and perceptual states have different kinds of content.

Since the argument is obviously valid, the question to ask is whether its premises are true. In what follows I spell out in detail each of the premises, so that I can discuss their veracity.

${ }^{7}$ Heck calls conceptual states "cognitive states", but here, to avoid confusion, I will call them conceptual states. 


\subsection{The First Premise}

The first conjunct of the first premise in Heck's argument is that conceptual states satisfy the Generality Constraint. Heck thinks that it is an empirical fact that conceptual states meet the Generality Constraint. He says:

beliefs arguably satisfy what Evans called the "generality constraint": A thinker who is capable of entertaining the thought that $a$ is $F$ and is also capable of entertaining the thought that $b$ is $G$ will typically also be capable of entertaining the thought that $a$ is $G$ and that $b$ is $F$. (pp. 121$122)^{8}$

The second conjunct in Heck's first premise is that perceptual states do not meet the Generality Constraint. Heck, however, does not really show this, but merely explains some ways in which perceptual states may fail to meet the constraint. He thinks that perceptual states have a number of characteristics that make it unlikely that they generalize in the way that conceptual states do. Perceptual states, thinks Heck, are more similar to "cognitive maps" ceptual states, in several ways. First, both for cognitive maps and perceptual states there is no unique structured proposition that might give their content. Second, only some kinds of propositions are suited to be the contents of perceptual states; for example, these states

${ }^{8}$ The next sentence of this quote is: "Thought, that is to say, is productive and systematic in much the same way that language is." At an oral presentation of a previous version of this paper, I was asked if my argument against Heck's argument goes through if I take Heck as claiming just that, as a matter of empirical fact, conceptual states are systematic and productive. I think my argument still works. It is not clear how much and what kind of systematicity and productivity conceptual states involve. Under some interpretations of what would make representational states systematic, even language and thought are not systematic. See Johnson 2004 for a defense of this. Under other interpretations, it is not clear that perceptual states are not systematic and productive. There could be a way of understanding systematicity and productivity in which perceptual states turn out to be systematic and productive. Fodor, in his "Revenge of the Given" (2007), for example, claims that all representational states (including perceptual states) are productive and systematic, and because of this both conceptual representations and perceptual representations are compositional (pp. 5-6).

${ }^{9}$ Cognitive maps are a type of mental processing composed of a series of psychological transformations by which an individual can acquire, code, store, recall, and decode information about the relative locations and attributes of phenomena in their everyday spatial environment. The purpose of a cognitive map is to integrate and apply environmental information using a representation that is built inside the head for the individual's personal use. 
cannot have disjunctions or negations as their contents. Finally, what perceptual experiences represent explicitly is very specific. According to Heck, for example, we do not explicitly perceive that something is blue, but instead we always perceive very specific shades of blue. ${ }^{10}$ Heck claims that these characteristics of perceptual states suggest that they may fail to meet the Generality Constraint. However, Heck does not really have any empirical evidence for this claim, but limits himself to giving two hypothetical ways in which perceptual states could fail to meet the Generality Constraint.

The first way is a consideration about how depth perception functions. Heck claims that depth perception may be locally limited, so that relative distance from the subject is explicitly represented only for objects that are near one another in the visual field. Thus, for example, one object might be represented as closer than another that is but a short angular distance from it, and that object as farther away than another a short angular distance from it. But it could be the case that no such relationship between the first object and the third is explicitly represented at all. If this were the case, the Generality Constraint would not be satisfied, since it would not follow from the fact that one could perceive that $a$ is closer than $b$ and that $b$ is closer than $c$ that one could also perceive that $a$ is closer than $c$.

The second way is a consideration about the phenomenon of color constancy. Heck asks us to assume that one can visually perceive as explicitly uniform in color only small connected surfaces. If this were the case, claims Heck, the Generality Constraint would fail. " $x$ is the same color as $y$ " would be explicitly representable only under certain circumstances, for example, when $x$ and $y$ were points on a small connected surface.

Heck admits that he does not have empirical evidence for his claim that perceptual states fail to meet the Generality Constraint, but believes that his considerations of the differences between conceptual

\footnotetext{
${ }^{10}$ The relevant difference here between what one explicitly perceives and what one only perceives implicitly is analogous to the one that is often made between implicit and explicit belief. The idea is that only explicit beliefs are stored in the subject's head, while implicit beliefs are those beliefs that can be inferred from explicit beliefs but are not really in the subject's head. It is explicit beliefs that are the inputs to reason, while implicit beliefs can be the output. In a similar way, what one perceives implicitly is the input to the computational processes that have as outputs beliefs about what one perceives. Heck believes that our perceptual inputs are a lot more specific than our beliefs about them, so that we really perceive explicitly, for example, very specific shades and shapes. We only perceive very specific color shades, for example, while concepts of colors emerge at a later stage, when we are coming to have a belief about what we perceived.
} 
states and perceptual states, plus these two indications as to how it may be the case that perceptual states fail to meet the Generality Constraint, are enough for his argument to run. ${ }^{11}$

\subsection{The Second Premise}

The second premise of the argument rests on a more general principle concerning what would be sufficient for states to have different kinds of content: that states have different kinds of content if their contents have different kinds of structure. What takes us from this general principle to the claim in Heck's second premise is how, according to Heck, we can tell what kind of structure a given content has.

Heck's idea is that the kind of structure we should attribute to a given content should respond to our explanatory purposes. What we want is to be able to explain, by attributing a certain structure to the content of kinds of states, why such states satisfy the generalizations that they satisfy. The kind of structure we should take the content of mental states to have should reflect causally relevant structural

${ }^{11}$ It is not clear to me whether Heck's hypothetical examples of perceptual states failing to satisfy the Generality Constraint are clear enough to help him make his point. The first example concerns our inability to represent explicitly some relative distances, the second one concerns our inability to represent sameness of shades of color in certain circumstances. In both examples what is at issue is not any inability to combine representations, which is what satisfying the Generality Constraint seems to require according to Heck's own version of it, but our inability to make some transitive perceptual inferences, in the first case, and our inability to perceive similarities in some circumstances, in the second case. It is not clear that these cases have anything to do with whether perceptual states meet the Generality Constraint. These cases, if veridical, would show that under certain circumstances we do not in fact perceive some relative distances or we do not in fact perceive similarities in color, but this does not mean that we could not perceive them. Here it is relevant to make a distinction between competence and performance. Under the circumstances that Heck considers for his examples, we do in fact fail to perceive some relative distances or some similarities in color, but does this mean that we are unable in general to perceive relative distances or similarities in color? I think that the examples, if true, would only show that there are situations in which we find ourselves in which we fail to perform optimally in respect of what we perceive, but this does not mean that we do not have the competence, or the ability, to perceive what in some circumstances we do not perceive. Heck needs his examples to be about competence, because the Generality Constraint is a constraint on competence, not on performance, but I am not sure that Heck's examples really are about competence. It seems to me that Heck's examples fail to support the claim that, under every circumstance, we are unable in principle to make transitive perceptual inferences about relative distances, or perceive similarities in color. My case against Heck, however, does not rest on this concern, but rather, as I have said, on what Heck would need the Generality Constraint to be in order for his first premise to be true. 
features of those states, features that explain why those states satisfy the generalizations that they satisfy. ${ }^{12}$

But why should we attribute any structure at all to the content of the states? Why is it not enough to attribute structure to the representations involved in the states to explain why they satisfy the generalizations that they satisfy? Heck claims that by doing only this we would have incomplete explanations as to why the states satisfy those generalizations. It is not enough to claim that the states meet the generalizations they meet because the representations involved in them have parts; we also need to claim that those parts have contents in their own right and that each of these parts contributes its content to the content of the whole. His idea then is that the syntactic similarities (and differences) among the representations involved in a state are relevant in the explanation of why states satisfy the generalizations that they satisfy only because the syntax reflects the semantics.

So, according to Heck, if states of different kinds satisfy different kinds of generalizations, then we can claim that they have different kinds of content, since different kinds of structured content need to be attributed to explain the satisfaction by states of different kinds of generalizations. Heck uses the Generality Constraint as an example of a generalization whose satisfaction by states would imply that those states have a certain kind of structured content. If states do meet it, then this will imply that they have a certain kind of structured content, which states that do not meet it will therefore not have.

Thus, according to Heck, the fact that beliefs satisfy the Generality Constraint has to be explained, not only in terms of the representations that they involve, but also in terms of their content. He first considers what an explanation of why beliefs meet the Generality Constraint in terms of the representations that they involve would look like. He says:

Suppose that the representations underlying propositional attitudes are sentence-like (there is a LOT). The belief that $a$ is $F$ comprises a representation of the form $\Phi(\alpha)$, and the belief that $b$ is $G$ comprises one of the form $\Gamma(\beta)$. It is a fact about these representations that their parts are, normally, freely recombinable, so, normally, someone who can form the two representations $\Phi(\alpha)$ and $\Gamma(\beta)$ will also be able to form

${ }^{12}$ This requirement is related to the principle of compositionality, invoked among others by Fodor (2002) to explain the productivity and systematicy of thought. In fact, the Generality Constraint is often understood as referring to the systematicity of thought (but see footnote 8). 
the representations $\Phi(\beta)$ and $\Gamma(\alpha)$ and so to think that $b$ is $F$ and that $a$ is $G[\ldots]$. The fact that cognitive states satisfy the generality constraint $[\ldots]$ thus seems to be a consequence not of the kind of contents such states have but of facts about cognitive architecture. (p. 133)

Heck goes on to note, however, that this explanation is incomplete:

That someone capable of forming the representations $\Phi(\alpha)$ and $\Gamma(\beta)$ can also form the representations $\Phi(\beta)$ and $\Gamma(\alpha)$ is irrelevant unless the presence of the common feature $\alpha$ in $\Phi(\alpha)$ and $\Gamma(\alpha)$ signals some relevant similarity in the contents of these representations: If, that is to say, it is to follow that this person can think that $b$ is $F$ and that $a$ is $G$, the representations $\Phi(\beta)$ and $\Gamma(\alpha)$ need to have the contents that $b$ is $F$ and that $a$ is $G$. And to secure that conclusion, we need to regard the parts of these representations as having content in their own right and to regard the parts as contributing their contents to the content of the whole: we need, that is, to regard those representations as compositional [...]. The syntactic similarities are relevant only because of how the syntax is related to the semantics. (p. 135)

Thus, for Heck, what explains that conceptual states meet the Generality Constraint is, ultimately, that the contents of these states are structured in a way that mirrors how the representations involved in the states are structured; and this is so because the reason why representations are structured is that the contents are structured.

It is not my purpose here to discuss the second premise of Heck's argument. What I will do is criticize Heck's first premise, by showing that it is far from clear that there is a reading of the Generality Constraint that makes both conjuncts of the premise non-trivially true.

\section{The Generality Constraint}

In the previous section I explained Heck's argument, and what he claims about the Generality Constraint, without stopping to consider how the Generality Constraint is, or should be, understood. Here I will consider this issue more carefully, since whether Heck's argument is sound or not ultimately depends on whether there is a reading of the Generality Constraint that makes it so.

What is the Generality Constraint? It was Evans some 25 years ago who first introduced the Generality Constraint, although Evans, unlike Heck, first considered it in the course of explaining what would constitute acceptable theories of thought. Evans (1982) introduced the Generality Constraint by saying: "In discussing the nature 
of our conceivings we have little enough to go on, but there is one fundamental constraint that must be observed in all our reflections: I shall call it 'The Generality Constraint'" (1982, p. 100).

His idea was that our theories of thought should take thoughts as being essentially structured, which commits us to make certain claims about the thoughts that a thinking subject should be able to think. What he meant by the claim that thoughts are structured is that thoughts are a complex of the exercise of several distinct conceptual abilities. For example:

someone who thinks that John is happy and that Harry is happy exercises on two occasions the conceptual ability which we call "possessing the concept of happiness". And similarly someone who thinks that John is happy and that John is sad exercises on two occasions a single ability, the ability to think of, or think about, John. (1982, p. 101)

This claim about the structure of thoughts, Evans claimed, commits us to maintain the following: "if a subject can be credited with the thought that $a$ is $F$, then he must have the conceptual resources for entertaining the thought that $a$ is $G$, for every property of being $G$ of which he has a conception" (p. 104).

This is what Evans calls the Generality Constraint. What it says is that we can only attribute a particular thought to a subject if we are prepared to accept that such a subject is capable of entertaining a whole range of thoughts that involve the conceptual abilities that constitute that thought. We should not attribute the thought that $a$ is $F$ to a creature if we are not prepared to accept that such a creature could, in principle, predicate other properties of $a$ and predicate of other things that they are $F$. The Generality Constraint thus constrains our theories of thought because it prohibits us from attributing a thought to a subject unless that subject is capable of recombining the concepts or conceptual abilities manifested on that thought to form different thoughts.

In contrast, later theorists have used what they have called the Generality Constraint as a criterion to distinguish conceptual creatures from nonconceptual creatures (Camp 2004, Carruthers 2004, for example). Other theorists have used "the Generality Constraint" as a criterion for distinguishing conceptual states from nonconceptual states (Bermúdez 1998, for example), while yet others have used it to distinguish conceptual content from nonconceptual content (Crane 1992, Cussins 1990, Millar 1991, for example). Hence, 
theorists who have invoked "the Generality Constraint" have meant different things; so in considering Heck's argument it is important to ask what Heck should have in mind when he invokes the Generality Constraint, that is, what the Generality Constraint must be if his argument is to be sound.

We can see from Heck's argument that he intends to apply the constraint to states. He claims that conceptual states, but not perceptual states, satisfy it. Bearing this in mind, we can ask whether he thinks that satisfying the Generality Constraint is definitional of being a conceptual state, or if he thinks that it is an empirical contingent fact that conceptual states meet it. For Evans, and for other philosophers after him (Peacocke 1992, for example) part of what it is to be a thought is to satisfy the Generality Constraint, so there is no question as whether or not thoughts satisfy it. However, Heck seems to think that it is an empirical question whether a given state meets the Generality Constraint. In fact, for Heck it has to be an empirical question, since if it were a matter of definition of what is to be a conceptual state that it satisfies the Generality Constraint, his conclusion would become trivial. If by definition conceptual states are those mental states that satisfy the Generality Constraint, then nothing of interest would follow from the claim that conceptual states satisfy the Generality Constraint and perceptual states do not. It would be a mere stipulation.

To see the extent of the problem in having a version of the Generality Constraint that makes Heck's first premise true by stipulation, it is useful to make an analogy with the following sexist argument:

1. By stipulation, only women engage in female ways of thinking, so men do not.

2. If women engage in female ways of thinking and men do not, then women and men have different kinds of thoughts.

Therefore,

3. Women and men have different kinds of thoughts.

We can see that this argument really does not tell us anything of interest about how women and men think. It only gives us a trivial difference, one that follows from a stipulation. In a similar way, if the argument for content dualism that Heck proposes is going to tell us something substantial about the kinds of content that conceptual states and perceptual states have, it cannot be built into the very 
formulation of the Generality Constraint that perceptual states do not satisfy it, on pain of trivializing everything that follows from that stipulation. Thus, Heck needs a version of the Generality Constraint that can in principle be applied to both conceptual states and perceptual states, and that makes it an empirical question whether both kinds of states satisfy it.

Indeed, one of the main things I will argue in this paper is that there are some interpretations of the Generality Constraint that Heck cannot use for his argument, precisely because they stipulate that only conceptual states satisfy the Generality Constraint and therefore trivialize Heck's first premise. If Heck's conclusion that conceptual states and perceptual states have different kinds of content is to be taken as doing more than just pinpointing a stipulated difference, this conclusion ought not to be based on a stipulated premise.

The question one can ask in order to try to formulate an interpretation of the Generality Constraint that could serve for Heck's purposes is how strongly the Generality Constraint has to be interpreted. In what follows I will explain that both weaker and stronger interpretations of the Generality Constraint are possible. ${ }^{13}$ I will discuss different versions of the Generality Constraint, taking it as expressing an empirical fact about certain kind of representational states, so that we can express the constraint in terms of the recombinability of mental representations. Heck follows Evans in expressing the constraint first in terms of structured abilities, but one can say that the structured abilities that one needs to have for one's states to meet the Generality

${ }^{13}$ Heck himself makes a distinction between strong and weak readings of the Generality Constraint. He says:

In its weak form, the generality constraint simply states that there is a certain kind of pattern in our cognitive capacities. Satisfaction of this weak form of the generality constraint is not sufficient for states of a given kind to have structured contents. One can imagine that a creature's cognitive capacities should exhibit this sort of pattern even though there is no substantial sense in which that creature's ability to entertain the thought that $a$ is $F$ involved the exercise of distinct abilities to think of $a$ and to think of a thing as $F$. [ ...] the generality constraint must be satisfied in the stronger form $[\ldots]$. The ability to think that $a$ is $F$ must decompose into the abilities to think of $a$ and to think of a thing as $F$, abilities that are sufficiently distinct that one's being able to think that $a$ is $F$ may be explained by one's being able to think of $a$ and one's being able to think of a thing as $F$. (2007, p. 123)

All the versions of the constraint I will consider fall within Heck's strong interpretation. 
Constraint are abilities to represent $a$, to represent $b$, to represent $F$, etc. Bearing in mind this way of expressing matters, the Generality Constraint can be interpreted in different ways within a spectrum that goes from a very weak interpretation, under which for a state to meet the Generality Constraint it needs to involve representations that recombine only in very limited ways with other representations, to a very strong interpretation, under which for a state to meet the Generality Constraint, it needs to involve representations that recombine with other representations in a much more expansive way. It is useful to first consider the interpretations on the extremes of the spectrum to see what would happen to Heck's argument under those interpretations, so I will start considering the weakest and strongest possible interpretations. Since none of these extreme interpretations are really what Heck could have in mind, I will then consider several intermediate interpretations.

\subsection{The Weak Interpretation}

The weakest possible reading of the Generality Constraint is one under which, for a mental state of a subject to satisfy it, it merely needs to involve representations that can combine with at least one other representation to figure in at least one other mental state of the subject. Thus:

(GCW) A representational state $S$ of a subject $P$ satisfies the GC if and only if $S$ involves representations $a, b, c \ldots$ as proper constituents, and each of $a, b, c \ldots$ can combine with some other representation $d, e, f$ that $P$ has, to be the constituent of other, differently constituted, representational states $S^{*}, S^{* *}, \ldots$ of $P .^{14}$

We can see that under this interpretation, meeting the Generality Constraint involves a very limited ability to recombine representations. Indeed, GCW makes meeting the Generality Constraint so easy that, not only conceptual states, but also nonconceptual states meet it. There is nothing in principle that stops states that we would consider to be paradigmatic nonconceptual states, such as perceptual states, from meeting the Generality Constraint in the weak interpretation.

${ }^{14}$ There is a possible reading of the GC that is even weaker than this one, in which it is only needed that one of the representations $a, b, c \ldots$ involved in the state combine with another representation $d, e, f \ldots$ to form at least one other representational state. The difference between this weaker version and GCW will not really matter for the present discussion. 
Indeed, it is plausible that satisfying GCW is a necessary condition for a state's being representational. José Luis Bermúdez (1998), for example, claims that if states of an organism are to be considered representational states at all, they should satisfy the following four criteria:

1. They should serve to explain behavior in situations where the connections between sensory input and behavioral output cannot be plotted in a lawlike manner.

2. They should admit of cognitive integration, which means that there must be inferential pathways enabling them to connect up with other states, both representational and motivational. ${ }^{15}$

3 . They should be compositionally structured in such a way that their elements can be constituents of other representational states.

4. They should permit the possibility of misrepresentation. (1998, p. 94)

If we consider that it is plausible to demand that the elements of all representational states have to allow for recombination with the elements of other representational states, as Bermúdez's third criterion demands, then it looks as if we have to say that all representational states are conceptually structured. If we agree to demand from all representational states that they meet GCW, then it would be false that perceptual states fail to meet it, since we take them to be representational states. It follows that, under the GCW interpretation of the Generality Constraint, Heck's first premise is false, since it is false that perceptual states do not satisfy the Generality Constraint. ${ }^{16}$

${ }^{15}$ This point is familiar in the context of propositional attitudes. Part of what it is to have a belief is that it should be open to modification from newer incompatible beliefs, or that it should be capable of being put together with a desire in an inference to produce behavior.

${ }^{16}$ Notice here that even if we grant Heck his claim that the representations in perception are more specific than the representations in conceptual thought, it does not follow that these more specific representations could not combine in the way that the weak version of the Generality Constraint requires. It seems intuitively plausible that if one can represent a given piece of the visual field as being a very specific shade of blue, one could, in principle, also represent another given piece of the visual field as being the same very specific shade of blue. It also seems plausible that one could at some point represent a given piece of the visual field as being a very specific shade of blue, and at another different point as being another very specific shade of blue. 


\subsection{The Strong Interpretation}

So, it is questionable at best and probably false that perceptual states do not meet the Generality Constraint under GCW. Can we make true the claim that perceptual states do not meet the Generality Constraint by interpreting it more strongly? Let us see what happens to Heck's claim that conceptual states satisfy the Generality Constraint and perceptual states do not when one makes what I think is the strongest possible interpretation of the Generality Constraint.

Under the strongest interpretation of the Generality Constraint, for a mental state of a subject to satisfy it, it needs to involve representations that can combine with any of all of the other representations that the subject has. Thus:

(GCS) A representational state $S$ of a subject $P$ satisfies the GC if and only if $S$ involves representations $a, b, c \ldots$ as proper constituents and each of $a, b, c \ldots$ that $S$ has can combine with all other representations $d, e, f \ldots$ that $S$ has to be the constituents of other, differently constituted, representational states $S^{*}, S^{* *}, \ldots$ of $P$.

Under the strongest interpretation of the Generality Constraint, it seems true that perceptual states do not meet it, but we encounter the problem that it also seems as if conceptual states do not meet it. Indeed, it seems that it would be impossible for any state to meet it, since there are absolutely no states of a thinking subject that involve representations that can just recombine with any other representation that the subject has. To see how implausibly strong GCS is, consider the following example. Suppose that a subject has a conceptual state involving the representations "Mary" and "run", such as the belief that Mary runs, and another conceptual state involving the representations "kites" and "sky", such as the desire to see kites in the sky. In order for those states to satisfy GCS it would have to be possible for that subject to, for example, have the belief "Sky Mary kites run". But does it really make sense to say that a subject can have a representational state "Sky Mary kites run"? In fact, if one believes that representational states have to be semantically evaluable, then one may think that "Sky Mary kites run" does not even count as a representational state, since it is not semantically evaluable. Thus, it seems that under GCS even conceptual states such as the belief that Mary runs and the desire to see kites in the sky fail to meet the Generality Constraint. Thus, GCS would render Heck's first premise false, since neither perceptual 
states, nor conceptual states, would satisfy the Generality Constraint. GCS is so strong that no representational state could satisfy it.

In conclusion, Heck's argument requires an interpretation of the Generality Constraint that lies somewhere between GCW and GCS. There are several different intermediate interpretations of the Generality Constraint, but as I will soon show, none of these make Heck's second premise true in a non-trivial way.

\subsection{The Intermediate Interpretations}

The lesson to be learned from my discussion of GCS is that, in order for states of a subject to satisfy the Generality Constraint, the subject should not be required to be able to have states involving representations that can combine indiscriminately. If this were required, then no states would satisfy the Generality Constraint. It seems then that representations can recombine only within certain limits, in other words, respecting certain restrictions. Bearing this in mind, it seems that in looking for an intermediate interpretation of the Generality Constraint we should try to find one that restricts the amount of recombination that has to occur among representations in order for states involving them to satisfy the constraint.

Now, such an intermediate interpretation cannot just make conceptual states meeting the Generality Constraint a matter of mere stipulation, for the reasons I explained at the beginning of section 2 . If something about the nature of the contents is supposed to follow from the nature of the states, then one must find an intermediate interpretation that does not merely stipulate that conceptual states satisfy the Generality Constraint and perceptual states do not. We cannot just say, for example, that the Generality Constraint is such that only those states that satisfy whatever restrictions are satisfied by conceptual states meet it. If we did this we would be defining the Generality Constraint in terms of conceptual states, thus eliminating the possibility of applying the Generality Constraint to anything that is not a conceptual state.

The problem, as I will explain, is that finding an intermediate interpretation that does not trivialize the claim that conceptual states meet the Generality Constraint and perceptual states do not is no easy task. I can see three ways in which the Generality Constraint can be interpreted that lie between GCW and GCS, all involving one or another kind of restrictions as to how much recombination among representations is needed to satisfy it. The first one involves some syntactic restrictions, the second one involves categorial restrictions, 
and the third one involves modular restrictions. However, it seems that two of these versions of the Generality Constraint seem to rely on characteristics that are definitional of conceptual states. They make the Generality Constraint unfit to be applied to perceptual states. This makes the issue of whether perceptual states fail to meet the constraint a matter of stipulation, making Heck's argument first premise true, but trivially so, thus trivializing Heck's argument. And as I will show, on the versions of the Generality Constraint that do not have this problem, Heck's second premise is false.

\subsubsection{Syntactic Restrictions}

One way of restricting the amount of recombination among representations required to satisfy the Generality Constraint is suggested by Evans's (1982) original formulation of the constraint, and by most formulations after his, including Heck's. The Generality Constraint is usually expressed in terms of the capacity to recombine in thought different syntactic subjects with different syntactic predicates, very much in the way that in language one can recombine grammatical subjects with grammatical predicates. In Evans's original formulation, meeting the Generality Constraint required being able to combine $a$ 's with $F$ 's and $G$ 's, and $b$ 's with $F$ 's and $G$ 's, but not $a$ 's with $b$ 's and/or $F$ 's with $G$ 's. His formulation presupposed the syntax of a small fragment of predicate logic (the atomic part). This means that meeting the Generality Constraint involved, from the outset, a restricted kind of generality, one that required the capacity to think different thoughts of the subject-predicate kind, but did not require the capacity to recombine all of one's representations with one another.

Thus, maybe what Heck has in mind is this kind of intermediate version of the Generality Constraint, which requires being able to combine all of one's subject-representations with all of one's predicate-representations.

This is still a strong version of the Generality Constraint, though less so than the GCS. In fact, one could argue that it is still too strong for Heck's purposes since, although it is true that perceptual states would not satisfy the constraint under this version, it is likely that conceptual states would not either. It is plausible to claim that a state of a subject can be conceptual even when one or more of the subject-representations involved in the state cannot recombine with all the predicate-representations that the subject has.

However, this is not the main problem with this interpretation. The main problem is that it appeals to the syntax of predicate logic, 
and there is no reason to think that perception (or thought!) has that sort of syntax. Why appeal to this kind of syntax as opposed to some other kind of syntax? And the answer cannot be "because this syntax is the one that conceptual states have", since then we would be defining the Generality Constraint in terms of conceptual states. Under this version of the constraint perceptual states do not satisfy the Generality Constraint because they do not have the appropriate syntax, but this is because by definition only states with the syntax of conceptual states satisfy the constraint, and this is why it would not be an empirical question whether perceptual states do so. In other words, perceptual states would not satisfy the Generality Constraint, but this would be so by stipulation, just because they do not share the syntax of conceptual states.

The next kind of intermediate version I will consider restricts the recombination required by the constraint in a different way, but as I will explain, it has a parallel problem to the one I have just explained.

\subsubsection{Categorial Restrictions}

There is a possible interpretation of the Generality Constraint that imposes some categorial restrictions to the recombination of representations required to satisfy the constraint. Evans himself seemed to think that we should make "categorial restrictions", when he added the following caveat to the Generality Constraint in a footnote: "with a proviso about the categorical appropriateness of the predicates to the subjects" (1982, p. 101 fn). Peacocke's version of the Generality Constraint also seems to include categorial restrictions:

If a thinker can entertain the thought $F a$ and also possesses the singular mode of presentation $b$, which refers to something in the range of objects of which the concept $F$ is true or false, then the thinker has the conceptual capacity for propositional attitudes containing the content Fb. (Peacocke 1992, p. 42) ${ }^{17}$

${ }^{17}$ Although the Generality Constraint mostly continues to be expressed in terms of capacities to recombine subjects with predicates, not everyone thinks that the Generality Constraint should involve categorial restrictions. Camp (2004) thinks that the Generality Constraint should be interpreted as not involving categorial restrictions. In her interpretation, one's states meet the Generality Constraint if one can combine all of one's representations of subjects with all of one's representations of predicates, whatever the categories they belong to. I explained above, however, the reasons why Heck cannot avail himself of this version of the constraint that imposes syntactic restrictions but not categorial restrictions. 
This version of the constraint, which imposes categorial restrictions, is also problematic for Heck's argument. The problem is that this version presupposes that the constraint applies to states that operate on representations of categories that are isomorphic to linguistic categories, and there is no reason to believe that perception operates over representations of categories isomorphic to linguistic categories. It is trivially true that perceptual states are not linguistic states, so if what the constraint requires is that the states to which it applies exhibit a recombination that respects linguistic categories, perceptual states do not satisfy it, but this is a trivial fact. They do not satisfy the constraint simply because they are not linguistic, therefore it is again not an empirical question whether they satisfy it, rendering Heck's second premise true but trivially so, and therefore again trivializing Heck's argument. Under this version of the Generality Constraint, it is established by stipulation that perceptual states do not satisfy the constraint, but again, this is not what Heck wants.

It seems that what Heck needs for his argument to work is an intermediate version of the Generality Constraint which does not stipulate that either the states to which it is applicable have the syntax attributed to conceptual states or that they operate over the categories that are usually attributed to conceptual states. I consider a version of the constraint that is both syntax- and category-neutral in what follows.

\subsubsection{Modular Restrictions}

So far I have argued that Heck's argument needs a version of the Generality Constraint that requires more recombination of representations than on GCW but less recombination than on GCS. This is because under GCW it is plausible that both conceptual states and perceptual states satisfy the constraint, while under GCS it is plausible that neither conceptual states nor perceptual states satisfy it. Heck's first premise claims that conceptual states satisfy the constraint and perceptual states do not, and he believes that this is not a trivial fact, but something that has to be established empirically. Therefore, he needs an intermediate version of the constraint that does not simply appeal to features of conceptual states, such as a syntax or a way of representing that could only apply to conceptual states, on pain of trivializing his argument.

Millikan's (2000) reflections about what distinguishes perceptual representations from conceptual representations suggest a different 
idea about how one could formulate another intermediate interpretation of the constraint. She says:

Perceptual representations that guide immediate action need to be rich in specific kinds of information, showing the organism's exact relations to a number of aspects of its current environment directly as they unfold during action. These representations may need to have variable structure of a kind that conforms closely to the variable structure of the organism-environment relations that need to be instantly taken into account. And because they need to be constructed quickly and reliably, they may be constructed by modular systems that are relatively cognitively impenetrable $[\ldots]$. The first job of the more disinterested, more general-purpose, cognitive representations, on the other hand, is easy participation in mediate inference. This job makes different demands, there being no way to specify in advance in what specific kinds of inference such a representation may need to be used. (2000, pp. 200-201; the italics are mine.)

Millikan's idea is that perceptual representations may be constructed by modular systems. So a way to think about the extent of recombination of representations of different kinds of states would be in terms of how different states belong to different modules and the representations within the different modules recombine to different extents with the representations of other modules. Modules are dedicated domain-specific cognitive mechanisms, that can be more or less cognitively impenetrable (interact to different extents with other modules). Thus, one could formulate an intermediate version of the Generality Constraint in terms of recombination of representations across modules, imposing some modular restrictions.

Interestingly, within this modular reading of the constraint, we can have weaker and stronger readings, and none of the ones I can think of make Heck's first premise true. Suppose that the mind was entirely divided in modules, as the massive-modularity theory claims. ${ }^{18} \mathrm{We}$ can have a modular weak interpretation $(\mathrm{GCMw})$ that reads like this:

(GCMw) A representational state $S$ in a module $M_{1}$ of a subject $P$ satisfies the GC if and only if $S$ involves representations $a, b$, $c .$. as proper constituents, and each of $a, b, c \ldots$ can combine with other representations $d, e, f \ldots$ within $M_{1}$ to be the constituent of other, differently constituted, representational states $S^{*}, S^{* *}, \ldots$ in $M_{1}$.

${ }^{18}$ For a review of the different modularity theories and arguments for and against them, see Barrett and Kurzban 2006. 
We can see that for a state to meet the modular weak Generality Constraint (GCMw), it would be enough, for example, that such a state was realized in a module that operated over structured representations and that these representations could recombine with one another within such a module. Therefore, for a subject's states to satisfy GCMw, she would only need to have this limited interaction between the structured representations within her modules. Assuming that this strictly modular model applies both to humans and animals, we can see why, under this modular weak interpretation, meeting the Generality Constraint is easy, and not exclusive, not even representative, of human thought. Perceptual states would satisfy GCMw if they involved representations that recombine within the perceptual modules, and animals are said to have perceptual modules. Thus, GCMw does not make Heck's first premise true, since it is plausible that, under it, perceptual states would meet the Generality Constraint.

A strong modular interpretation also will not make Heck's first premise true. It would read like this:

(GCMs) A representational state $S$ in a module $M_{1}$ of a subject $P$ satisfies the GC if and only if $S$ involves representations $a, b, c \ldots$ as proper constituents, and each of $a, b, c \ldots$ can combine with other representations $d, e, f \ldots$ in all of the other modules $M_{2}, M_{3}, \ldots$ of $P$, to be the constituent of other, differently constituted, representational states $S^{*}, S^{* *}$ of $P$.

It is easy to see why it would be impossible for any state to meet GCMs, including conceptual states. In the strictly modular view of the mind, it is obvious why. At least some modules involve representations that only interact with representations within that module. But even in a view of the mind that is not strictly modular, in the sense that it allows for both modules and something like a central system that can take some representations from the modules as inputs, the representations of the modules will only combine with representations within themselves and representations of the central system, but not representations in other modules. At the same time, representations of the central system will not have access to all the representations within the modules. So, there would be no states, not even the states of the central system, which involve representations that can combine with any other representation the subject has. Thus, we can see that no states satisfy GCMs, making Heck's first premise 
false, since neither perceptual states nor conceptual states would meet the Generality Constraint.

Thus, it seems that Heck would need a modular interpretation that lies somewhere between GCMw and GCMs. So now the question is what such an intermediate version would be like in the light of a modular view of the mind. Consider this one:

(GCMi) A representational state $S$ in a module $M_{1}$ (or the central system) of a subject $P$ satisfies the GC if and only if $S$ involves representations $a, b, c \ldots$ as proper constituents, and each of $a, b, c \ldots$ can combine with other representations $d$, $e, f \ldots$ of some of the other modules $M_{2}, M_{3}, \ldots$, to be the constituent of other, differently constituted, representational states $S^{*}, S^{* *}$ of $P$.

Does an interpretation like GCMi make Heck's argument's first premise true? According to GCMi, states satisfy the Generality Constraint if the representations they involve recombine with representations across some different modules. Under this version, it is plausible that conceptual states satisfy the Generality Constraint because under modular theories of the mind, conceptual states involve representations that take as inputs representations of different modules. This is so no matter whether one has in mind a strictly modular view of the mind (what is known as the massive modularity view), or a view in which the mind has both modules and a central system (in which conceptual states are states of the central system). Both the states of the conceptual modules (in the massive modularity view) and the states of the central system (in the modules-central system view) are supposed to take as inputs representations from other modules; although not from all of the other modules, since allegedly the degree of encapsulation of the different modules varies, and some of the modules operate over representations that are not available to the conceptual modules or the central system. So, under GCMi it makes sense to claim that conceptual states satisfy the constraint.

What about perceptual states? What would make perceptual states fail to satisfy GCMi? This would be so if the representations that they involve did not combine with representations in modules that are not perceptual, or representations of the central system. The problem is that perceptual representations are supposed to combine with the representations of other modules or the central system, since they supposedly serve as inputs for other modules and/or the central system. Perceptual representations, for example, are supposed to stand 
in inferential (justificatory) relations with conceptual representations. For this to be the case, perceptual representations have to be recombinable with representations of the conceptual modules or the central system.

Therefore, it seems that under GCMi, Heck's first premise is also false, since under it perceptual states do meet the Generality Constraint. Thus, none of the modular interpretations of the Generality Constraint make Heck's premise true. Thus, even when on these three different versions of the modular interpretation the satisfaction of the Generality Constraint by kinds of representational states is an empirical matter, and not a stipulation, none of them make Heck's first premise true. So, on the interpretations that do not trivialize Heck's argument, the argument is not sound.

\section{Conclusion}

Heck's argument for the distinction between kinds of content rests on the assumption that it is an empirical fact that conceptual states meet the Generality Constraint and perceptual states do not. I have examined this empirical assumption under different interpretations of the Generality Constraint. I have shown that under none of the interpretations is Heck's empirical assumption true. The weak interpretation $(\mathrm{GCW})$ makes the claim that perceptual states do not meet the Generality Constraint false, and the strong interpretation (GCS) makes the claim that conceptual states meet the Generality Constraint false. This led me to consider an intermediate interpretation of the constraint, one that would situate half-way between GCW and GCS.

I examined three different ways to make an intermediate interpretation of the constraint, and showed that two of them have the problem that they make Heck's first premise become a stipulation and therefore trivialize it, so they are not plausible interpretations of the constraint for Heck's purposes. Heck's argument needs the claim that conceptual states meet the constraint and perceptual states do not to be an empirical claim, otherwise his argument becomes trivial. He is looking for a substantial difference between conceptual states and perceptual states that can serve him to argue that they have different kinds of content. But if the difference in question is a matter of stipulation then his argument is trivialized. If the Generality Constraint is defined so that only conceptual states meet it, then it is trivially true that perceptual states do not satisfy it, and no interesting conclusion concerning the contents of conceptual and perceptual states would follow from such a stipulation. 
The third way to make an intermediate interpretation that I examined involved three versions of a modular reading of the constraint. I explained that, even though under any of the three modular interpretations Heck would not have the trivializing problem, under none of them is it true both that conceptual states meet the Generality Constraint and that perceptual states do not meet it. Thus, all of the three modular interpretations make Heck's first premise false, and therefore render Heck's argument unsound.

The question of whether there is a plausible interpretation of the Generality Constraint that would render Heck's first premise nontrivially true remains open. But I think I have shown that until such an interpretation is provided, the soundness of Heck's argument is dubious. ${ }^{19}$

\section{REFERENCES}

Barrett, H.C., and R. Kurzban, 2006, "Modularity in Cognition: Framing the Debate", Psychological Review, vol. 113, pp. 628-647.

Bermúdez, J.L., 1998, The Paradox of Self-Consciousness, MIT Press, Cambridge, Mass.

Brewer, B., 2005, "Does Perceptual Experience Have Conceptual Content?", in Sosa and Steup 2005, pp. 217-230.

Byrne, A., 2005, "Perception and Conceptual Content", in Sosa and Steup 2005, pp. 231-250.

Camp, E., 2004, "The Generality Constraint, Nonsense and Categorial Restrictions", Philosophical Quarterly, vol. 54, pp. 209-231.

Carruthers, P., 2004, "On Being Simple Minded", American Philosophical Quarterly, vol. 41, no. 3, pp. 205-220.

Cohen J. and B. McLaughlin (eds.), 2007, Contemporary Debates in Philosophy of Mind, Blackwell, Oxford.

Crane, T., 1992, "The Nonconceptual Content of Experience", in T. Crane (ed.), 1992, The Contents of Experience, Cambridge University Press, Cambridge, pp. 139-161.

Cussins, A., 1990, "The Connectionist Construction of Concepts", in Margaret Boden (ed.), 1990, The Philosophy of Artificial Intelligence (Oxford Readings in Philosophy), Oxford University Press, Oxford, pp. 380-400.

${ }^{19}$ Previous versions of this paper were presented at the II Conference UT, AustinUNAM, in Mérida, México, in 2007, and at the XIII Encuentro Iberoamericano de Filosofía Analítica, in Santiago de Compostela, Spain, in 2008. I thank audiences at both events for their valuable comments. I also want to thank two anonimous referees for their feedback, which I am sure has improved this paper greatly. I specially want to thank Lenny Clapp for his invaluable help reading and commenting on too many drafts of this paper. 
Evans, G., 1982, The Varieties of Reference, Oxford University Press, Oxford.

Fodor, J., 2007, "Revenge of the Given", in Cohen and McLaughlin 2007, pp. 105-116.

—_, 2002, "Language, Thought and Compositionality", Mind and Language, vol. 16, no. 1, pp. 1-15.

Heck, R., 2007, “Are There Different Kinds of Content?", in Cohen and McLaughlin 2007, pp. 117-138.

- 2000, "Non-Conceptual Content and the "Space of Reasons", Philosophical Review, vol. 109, no. 4, pp. 483-523.

Johnson, K., 2004, "On the Sistematicity of Language and Thought", Journal of Philosophy, vol. 101, no. 3, pp. 111-139.

Kelly, S, 2001, “The Nonconceptual Content of Perceptual Experience: Situation Dependence and Fineness of Grain", Philosophy and Phenomenological Research, vol. 62, no. 3, pp. 601-608.

Martin, M., 1993, "The Rational Role of Experience", Proceedings of the Aristotelian Society, vol. 93, pp. 71-88.

McDowell, J., 1994, Mind and World, Harvard University Press, Cambridge, Mass.

Millar, A., 1991, Reasons and Experience, Oxford University Press, Oxford. Millikan, R., 2000, On Clear and Confused Ideas: An Essay on Substance Concepts, Cambridge University Press, Cambridge.

Peacocke, C., 2001, "Does Perception Have a Nonconceptual Content?", Journal of Philosophy, vol. 98, pp. 239-264.

- 1998, "Nonconceptual Content Defended", Philosophy and Phenomenological Research, vol. 58, pp. 381-388.

- 1992, A Study of Concepts, MIT Press, Cambridge, Mass.

Prinz, J., 2002, Furnishing the Mind, MIT Press, Cambridge, Mass.

Robbins, P., 2002, "The Paradox of Self-Consciousness Revisited", Pacific Philosophical Quarterly, vol. 83, pp. 424-443.

Sosa E. and M. Steup (eds.), 2005, Contemporary Debates in Epistemology, Blackwell, Oxford.

Speaks, J., 2005, "Is There a Problem about Nonconceptual Content?", Philosophical Review, vol. 114, no. 3, pp. 359-398.

Stalnaker, R., 1995, “What Might Nonconceptual Content Be?", Philosophical Issues, vol. 9, pp. 95-106.

Tye, M., 2005, "Nonconceptual Content, Richness and Fineness of Grain", in T. Gendler and J. Hawthorne (eds.), Perceptual Experience, Oxford University Press, Oxford, pp. 504-530.

Received: September 4, 2008; revised: July 3, 2009; accepted: August 5, 2009. 